\title{
Does the orientation of syndesmosis fixative device affect the immediate reduction of the distal tibiofibular joint?
}

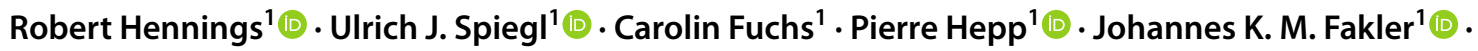 \\ Annette B. Ahrberg ${ }^{1}$ (D)
}

Received: 27 April 2021 / Accepted: 13 July 2021 / Published online: 7 August 2021

(c) The Author(s) 2021

\begin{abstract}
Introduction Incongruent stabilization of the distal tibiofibular joint (syndesmosis) results in poorer long-term outcome in malleolar fractures. The aim was to analyze whether the orientation of the syndesmotic stabilization would affect the immediate reduction imaged in computed tomography $(\mathrm{CT})$.

Materials and methods The syndesmotic congruity in 114 ankle fractures with stabilization of the syndesmosis were retrospectively analyzed in the post-operative bilateral CT scans. The incisura device angle (IDA) was defined and correlated with the side-to-side difference of Leporjärvi clear-space ( $\triangle$ LCS), anterior tibiofibular distance ( $\Delta$ antTFD) and Nault talar dome angle $(\triangle \mathrm{NTDA})$ regardless of the stabilization technique and separately for suture button system and syndesmotic screw. Asymmetric reduction was defined as $\Delta \mathrm{LCS}>2 \mathrm{~mm}$ and $\mid \Delta$ antTFD $\mid>2 \mathrm{~mm}$.

Results Regardless of the stabilization technique, no correlation between the IDA and the $\Delta$ LCS $(r=0.069)$, the $\Delta$ antTFD $(r=0.019)$ nor the $\Delta$ NTDA $(r=0.177)$ could be observed. There were no differences between suture button system and syndesmotic screw. Asymmetrical reduction was detected in $46 \%$ of the cases, while sagittal asymmetry was most common. No association was found between the orientation of stabilization device and occurrence of asymmetrical reduction $(p>0.05)$. The results of suture button system and syndesmotic screw were comparable in this respect $(p>0.05)$.

Conclusion Poor correlation between the orientation of the stabilization device and the immediate post-operative congruity of the syndesmosis could be shown. In contrast to current literature, this study did not show difference of suture button system over syndesmotic screw in this regard. Careful adjustment of the fibula in anteroposterior orientation should be given special attention.
\end{abstract}

Keywords Syndesmosis · Tibiofibular · Syndesmotic screw · Suture button

\section{Introduction}

Ankle fractures are one of the most common fractures [1]. Up to $39 \%$ are associated with an instability of the distal tibiofibular joint (syndesmosis) requiring stabilization [2]. An anatomical reduction of the fracture components as well as the syndesmosis is the prerequisite for a good post-operative outcome and the prevention of post-traumatic arthrosis [3-6]. If a syndesmotic lesion is detected, reduction and stabilization of the fibula position in the tibia incisura is

Robert Hennings

robert.hennings@medizin.uni-leipzig.de

1 Department of Orthopaedics, Traumatology and Plastic Surgery, University of Leipzig, Liebigstr. 20, 04103 Leipzig, Saxony, Germany indicated. With the static syndesmosis screw (SYS) and the flexible Suture Button System (SBS), equivalent stabilization methods are available for this purpose [8-10]. The general recommendation is to perform stabilization in an ascending orientation from posterolateral to anteromedial in the transversal plain at an angle of $20-30^{\circ}$ with the foot in neutral position [7]. In contrast, two recent studies examining the orientation of the stabilization in relation to individual anatomy recommend a reduced ascending orientation of $18.8^{\circ}[8,9]$. Furthermore, several computed tomographic (CT) analyses revealed significant interindividual anatomic differences of the syndesmosis [10-12]. By identifying risk factors and improving surgical technique, syndesmotic malreduction rates were reduced from $52 \%$ to around $20 \%$ with superiority of SBS [13-16]. However, the studies available have shown that stabilization of the syndesmosis is still a 
critical surgical step and syndesmotic asymmetry is associated with worse post-operative results [5, 14, 17]. With all studies already conducted in this field, there is still lack of evidence about the relationship between the rate of syndesmotic incongruity and the orientation of the stabilization device $[9,18,19]$. Therefore, the aim of the study was to evaluate the influence of the orientation of the syndesmosis stabilization device on the immediate post-operative syndesmotic congruity imaged in computed tomography. The hypotheses of the study were that the orientation of the stabilization device has no influence on the immediate reduction result and both stabilization methods (SYS, SBS) are comparable in this respect.

\section{Patients and methods}

Approval of the local institutional review board was given beforehand (AZ 488/19-ek) and the study was conducted in accordance with the Declaration of Helsinki and the guidelines for Good Clinical Practice.

Consecutive adult patients who received surgical stabilization of the syndesmosis between 01/2010 and 12/2019 were included in this retrospective study. All fractures were classified in accordance with the Arbeitsgruppe für Osteosynthesefragen (AO) classification [7, 20]. Ankle fracture types $44-\mathrm{B}$ and $44-\mathrm{C}(N=183)$ were identified and stored pseudonymized in electronic data base using SPSS (version 24, Chicago, IL, USA) [7, 20]. Further inclusion parameters were post-operative bilateral CT control, anatomical stabilization of the fracture components, and an unsuspicious contralateral ankle without a history of ankle fractures in the past or other ankle deformities $(N=114)$. Exclusion criteria were degenerative alterations of the uninjured ankle and insufficient CT scans that did not include the fixation device. Additionally, patients with persistent bone step $>2 \mathrm{~mm}$ with non-anatomic reduction of the fractures were excluded, based on the finding that fibular shortening of $>2 \mathrm{~mm}$ after osteosynthesis represents an isolated risk factor for malalignment of the syndesmosis [21].

\section{Operative management}

All patients were treated according to the recommendations of the AO [11]. If not evident from the preoperative imaging, syndesmotic instability was evaluated under standard fluoroscopy (lateral and mortise view) following fracture stabilization using the hook test while the ankle was placed in neutral dorsiflexed position [7, 22-25]. After detecting the instability, reduction of the syndesmosis and stabilization was performed under direct visualization and fluoroscopy with a quadricortical, fully threaded $3.5 \mathrm{~mm}$ syndesmotic screw (DePuy-Synthes) or a suture button device
(TightRope ${ }^{\circledR}$, Arthrex, Naples, FL, USA) [22, 26]. All operations were performed by experienced specialists in ankle surgery of a trauma level I center. The surgeons decided which stabilization device to use based on their intraoperative assessment of bone quality, their experience with the devices and preference. In suspicion of osteoporosis, syndesmotic screws were used. Reduction and fixation were controlled by fluoroscopy intraoperatively.

\section{Groups}

Based on the stabilization procedure, two study groups were defined. The SYS group included patients who received a stabilization with a syndesmotic screw $(N=42 ; 37 \%)$ and the SBS group, who were stabilized using a suture button system $(N=72 ; 63 \%)$.

\section{CT scan image analysis}

All non-weightbearing CT scans were obtained during the in-patient period without administration of intravenous contrast medium as part of the standard care to assess syndesmotic reduction. Patients were positioned supine and feet first with the ankle in neutral position with both ankles in the same scanning field. Images were acquired using a multidetector CT scanner (iCT 256, Philips, Netherlands) Routine scan parameters included a tube current of $150 \mathrm{~mA}$, a tube voltage of $100 \mathrm{kV}$ with a collimation of $64 \times 0.625 \mathrm{~mm}$. Pitch was 0.329 with a rotation time of $0.5 \mathrm{~s}$. Multiplanar reformations were reconstructed in slice thickness of $0.67-2 \mathrm{~mm}$ in axial, sagittal and coronal orientation. Syndesmotic reduction was assessed $10 \mathrm{~mm}$ proximal of the ankle joint using validated landmark-based techniques according to Schon et al. [27, 28]. Measurements were made using SieNet MagicWeb (Siemens AG, Medical Solutions, Germany) by one experienced orthopedic and trauma surgeon who was trained in the measurement methods. The Leporjärvi Clear Space (LCS) was used to analyze the medial-lateral translation. The Nault talar dome angle (NTDA) was measured to evaluated the external rotation of the fibula (Fig. 1a and b) [27, 29, 30]. The anterior-posterior translation was assessed to define the anterior tibiofibular distance according to Ahrberg et al.(antTFD; Fig. 1c) [28]. These parameters were selected due to their high intra-observer and interobserver reliability in evaluating side differences as demonstrated in the literature and were assessed for both sides $[27,28]$. The side-to-side differences between injured and uninjured sides were calculated and defined as $\triangle \mathrm{LCS}$, $\triangle$ NTDA and $\triangle$ antTFD. Positive $\Delta$ LCS represented widening of the syndesmosis. Positive $\Delta$ antTFD was defined 

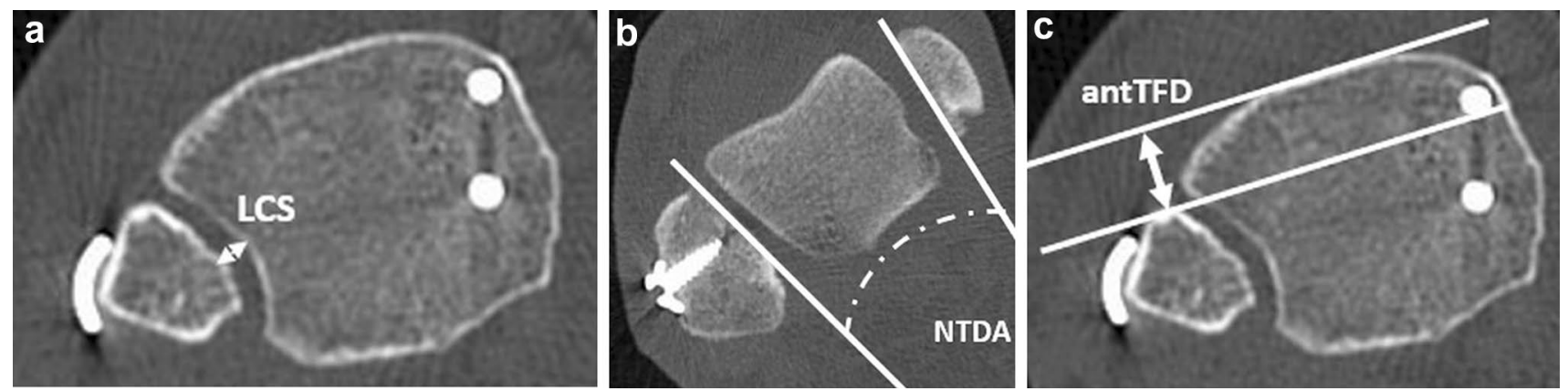

Fig. 1 Transversal plane of computer tomography $10 \mathrm{~mm}$ above the ankle joint demonstrate the measurement of Leporjärvi Clear Space (LCS; 2a), Nault talar dome angle (NTDA; 2b) and anterior tibiofibular distance (antTFD; 2c) at the injured ankle joint [28-30]

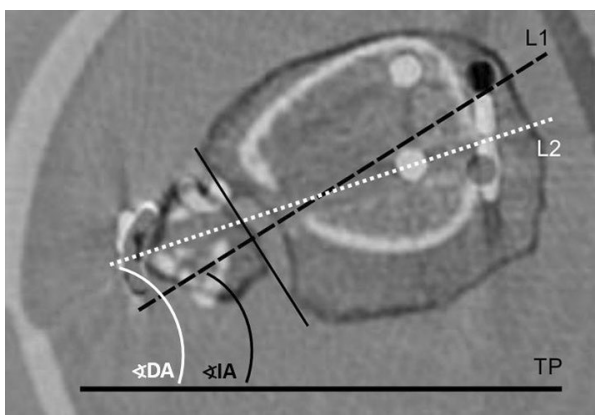

Fig. 2 Illustration of the transversal plane of computer tomography $10 \mathrm{~mm}$ above the plafond (black contours) and the plane at the level of the tibiofibular stabilization (white contours). L1 (black dashed line $)=$ perpendicular line crossing the midpoint between the anterior tubercle and posterior tubercle of the tibial incisura; L2 (white dotted line $)=$ tangent along the axis of the fixation device; $T P$ transversal plane; angle between L1 and TP = Incisura Angel (IA); angle between L2 and TP $=$ Device Angel (DA)

as a posterior translation of the fibula in relation to the tibia at injured side, whereas positive $\Delta$ NTDA represented an increased external rotation of the fibula of the injured side. $\Delta$ LCS $>2 \mathrm{~mm}$ and $\mid \Delta$ antTFDI of more than $2.0 \mathrm{~mm}$ were considered as asymmetrical syndesmotic reduction in accordance to literature $[5,15]$. The orientation of the syndesmotic fixation device and tibial incisura (SBS, SYS) was assessed as shown in Fig. 2, adapted from the technique used by Park et al. [8]. The measurement was performed $10 \mathrm{~mm}$ above the plafond in an axial plane. A tangent crossing the midpoint of the connection between the anterior tubercle to posterior tubercle of the tibial was defined as reference line 1 (line $1 ; \mathrm{L} 1)$ [12, 31]. The angle between L1 and the transverse plane (TP) was defined as Incisura Angle (IA, Fig. 2). To determine the orientation of the fixation device, the angle between the tangent along the axis of the fixation device (line 2; L2) and the TP was measured (Device Angle, DA, Fig. 2). Subtraction of the IA from the DA was defined as the incisura device angle (IDA).

\section{Statistics}

Statistical analysis was performed with SPSS software (Version 25, IBM, Chicago, IL, USA). The Student's $t$-test or Mann-Whitney $U$-test was used to compare continuous variables between the study groups. Categorical variables were compared using Pearson's Chi-square test or Fisher's exact test. Pearson correlation coefficients $(r)$ were used for correlation analysis and were interpreted as poor $(r<0.4)$, acceptable $(0.4<r<0.59)$, good $(0.6<r<0.74)$, or excellent ( $>r>0.74$ ) [32]. Differences between means with $95 \%$ confidence intervals $(95 \% \mathrm{CI})$ were calculated. Two-tailed $p$-values are presented. A $p$-value $p<0.05$ was considered to be significant. After applying the inclusion and exclusion criteria, the maximum sample size in this retrospective study was 114 patients. Power analysis showed that the minimum correlation coefficient considered significant was $r=0.328$ for $N=114$ and for the subgroups SBS (72 patients) $r=0.406$ and SYS (42 patients) $r=0.516$.

\section{Results}

The mean age of the patients was 44.5 years (18-85 years, SD 16.6). Men were younger than women $(p=0.001$; Table 1). In total, 72 patients (63\%) were stabilized with a suture button system (SBS group). The SBS group $(N=72)$ was younger compared to the SYS group (SYS group; $N=42 ; p=0.010$, Table 1 ).

Regardless of the fixation device, average IDA was $-10^{\circ}$ (SD $11^{\circ}$; range $-35^{\circ}$ to $16^{\circ}$ ). There was no difference between stabilization systems ( $p=0.893$; Table 2$)$. Regardless of the stabilization device, poor correlation between IDA and $\Delta$ LCS $(r=0.069), \Delta$ antTFD $(r=0.019)$ and the $\Delta$ NTDA $(r=0.177)$ could be observed (Table 1$)$.

In the separate analysis of the SBS group and SYS group, poor correlation was found between the IDA and $\triangle \mathrm{LCS}$, $\Delta$ antTFD or the $\triangle$ NTDA (Table 1 ). The mean $\triangle$ LCS and $\Delta$ NTDA were comparable between the groups $(p>0.05$; 
Table 1 Patients characteristics, fracture pattern and outcome for the total patient cohort and comparison of both stabilization procedures

\begin{tabular}{|c|c|c|c|}
\hline & \multicolumn{2}{|l|}{ All patients $N=114$} & \multirow[t]{2}{*}{$p$-value } \\
\hline & Women; $\mathrm{N}=52$ & Men; $N=62$ & \\
\hline Mean age in year (SD) & $50.2(18.1)$ & $39.6(13.5)$ & $0.001^{\mathrm{a}}$ \\
\hline IDA in & $-10(11 ;-35$ to 16$)$ & & \\
\hline$\Delta \mathrm{LCS}$ in $\mathrm{mm}$ & $0.5(1.6 ;-4.6$ to 5.5$)$ & & \\
\hline$\Delta$ antTFD in $\mathrm{mm}$ & $0,5(2,8 ;-7.7$ to 9.0$)$ & & \\
\hline$\triangle \mathrm{NTDA}$ in & $3.7(7.8,-30$ to 19 & & \\
\hline \multicolumn{4}{|c|}{ Correlation regardless types of stabilization $(r)$} \\
\hline IDA and $\Delta \mathrm{LCS}$ & 0.069 & & \\
\hline IDA and $\Delta$ antTFD & 0.019 & & \\
\hline \multirow[t]{3}{*}{ IDA and $\triangle$ NTDA } & 0.177 & & \\
\hline & \multicolumn{2}{|l|}{ Stabilization } & \\
\hline & SBS group; $N=72$ & SYS group; $N=42$ & \\
\hline age in year & $41.4(15.2 ; 18-80)$ & $49.6(17.7 ; 19-85)$ & $0.010^{\mathrm{a}}$ \\
\hline female: male & $34: 38: 00$ & $18: 24$ & $0.652^{\mathrm{b}}$ \\
\hline \multicolumn{4}{|c|}{ Anatomy and osteosyntheses of the fractures, $\mathrm{N}$} \\
\hline Isolated fibula & 25 & 13 & \\
\hline Fibula and medial mall & 12 & 7 & \\
\hline Fibula and posterior mall. ${ }^{c}$ & 17 & 5 & \\
\hline Fibula and posterior mall. ${ }^{\mathrm{d}}$ & 3 & 3 & \\
\hline Fibula, medial and posterior mall..$^{\mathrm{c}}$ & 11 & 9 & \\
\hline Trimalleolar fracture $^{\mathrm{d}}$ & 4 & 5 & \\
\hline IDA in ${ }^{\circ}$ & $-10(11 ;-35$ to 14$)$ & $-11(13 ;-32$ to 14$)$ & $0.893^{\mathrm{a}}$ \\
\hline$\Delta \mathrm{LCS}$ in $\mathrm{mm}$ & $0.6(1.5)$ & $0.4(1.8)$ & $0.580^{\mathrm{a}}$ \\
\hline$\Delta$ antTFD in $\mathrm{mm}$ & $0.9(2.6)$ & $-0.3(2.9)$ & $\mathbf{0 . 0 2 0}{ }^{\mathrm{a}}$ \\
\hline$\triangle \mathrm{NTDA}^{\circ}{ }^{\circ}$ & $4(8)$ & $3(6)$ & $0.415^{\mathrm{a}}$ \\
\hline \multicolumn{4}{|l|}{ Correlation $(r)$} \\
\hline IDA and $\triangle \mathrm{LCS}$ & 0.245 & -0.143 & \\
\hline IDA and $\Delta$ antTFD & -0.086 & 0.152 & \\
\hline IDA and $\triangle$ NTDA & 0.22 & 0.104 & \\
\hline
\end{tabular}

Bold $p$ values highlights significant differences

All data are presented as mean (SD; range). $\Delta$ side-to-side difference, IDA Incisura device angle, $L C S$ Leporjärvi Clear Space, antTFD =anterior tibiofibular distance, NTDA Nault talar dome angle, SBS suture button system, $S Y S$ syndesmostic screw

${ }^{\text {a }}$ Student's $t$-test

${ }^{\mathrm{b}} \chi^{2}$-test; mall. $=$ malleolus

${ }^{\mathrm{c}}$ Posterior malleolus no fixation

${ }^{\mathrm{d}}$ Posterior malleolus fixed

Table 1). AntTFD differed between both groups, with SBS positive in mean and SYS negative in mean $(p=0.020$; Table 1).

An isolated syndesmotic asymmetry according to $\Delta$ antTFD was seen in 38 patients (33\%), and in 11 patients $(10 \%)$ according to $\Delta$ LCS. A combined syndesmotic asymmetry ( $\Delta$ antTFD and $\Delta$ LCS) was visible in three patients $(3 \%)$. Thus, in a total of 52 patients $(46 \%)$ asymmetric syndesmosis was shown. Posterior translation was more common in the SBS group compared to the SYS group (SBS 22 vs SYS 9; $p \leq 0.003 ; r=0,389$ ). The mean IDA of patients defined as anatomically reduced $\left(-10^{\circ}\right)$ and those with a syndesmotic asymmetry was comparable for both $\Delta$ antTFD $\left(-12^{\circ} ; p=0.221\right.$, and $\Delta \operatorname{LCS}\left(-6^{\circ} ; p=0.282\right.$, Table 2). Furthermore, there was no difference assessing IDA between patients with anterior or posterior asymmetrical tibiofibular position ( $p=0.205$; Table 2$)$. The mean values of absolute LCS as well as $\Delta$ LCS of patients with anterior asymmetry were comparable to those of posterior asymmetrical tibiofibular position ( $p>0.05$; Table 2$)$. Poor correlation was evident between patients evaluated as 
Table 2 Overview of the reduction outcome and its relation with the parameters of interest. All data are presented as mean (SD)

\begin{tabular}{|c|c|c|c|}
\hline & \multicolumn{2}{|l|}{ Reduction outcome } & \multirow[t]{2}{*}{$p$-value } \\
\hline & Anatomical reduction & Asymmetric reduction ${ }^{*}$ & \\
\hline$\Delta$ antTFD N & 62 & 38 & \\
\hline IDA in $^{\circ}$ & $-10(11)$ & $-12(11)$ & $0.221^{\mathrm{a}}$ \\
\hline \multicolumn{4}{|l|}{ Correlation $(r)$ of } \\
\hline IDA and $\Delta$ antTFD & 0.024 & 0.08 & \\
\hline$\Delta \mathrm{LCS} N$ & 62 & 11 & \\
\hline IDA in ${ }^{\circ}$ & $-10(11)$ & $-6(12)$ & $0.282^{\mathrm{a}}$ \\
\hline \multicolumn{4}{|l|}{ Correlation $(r)$ of } \\
\hline \multirow[t]{2}{*}{ IDA and $\Delta \mathrm{LCS}$} & 0.024 & -0.363 & \\
\hline & Ant. asymmetry & Post. asymmetry & \\
\hline Malreduced acc. $\Delta$ antTFD $(N=38)$ & 10 & 28 & \\
\hline$\Delta$ antTFD in $\mathrm{mm}$ & $-4.1(2.1)$ & $3.7(2.0)$ & 0.013 \\
\hline IDA in $^{\circ}$ & $-16(13)$ & $-11(10)$ & $0.205^{\mathrm{b}}$ \\
\hline LCS in $\mathrm{mm}$ & $3.2(1.6)$ & $3.9(1.4)$ & $0.191^{\mathrm{b}}$ \\
\hline$\Delta \mathrm{LCS}$ in $\mathrm{mm}$ & $-0.1(1.9)$ & $0.5(1.3)$ & $0.310^{\mathrm{b}}$ \\
\hline$\Delta$ NTDA in ${ }^{\circ}$ & $3(7))$ & $6(6)$ & $0.299^{\mathrm{b}}$ \\
\hline
\end{tabular}

Bold $p$ value highlights significant differences

*Unidirectional malreduction; ant. = anterior, post. Posterior, IDA incisura device angle, LCS Leporjärvi Clear Space, antTFD anterior tibiofibular distance, NTDA Nault talar dome angle

${ }^{\mathrm{a}}$ student $t$-test

${ }^{\mathrm{b}}$ Mann-Whitney $U$ Test

having anterior, respectively, posterior tibiofibular asymmetry and IDA, $\Delta$ LCS or $\Delta$ NTDA $(-0.200<r<0.200)$.

\section{Discussion}

The hypotheses of the study were that the orientation of the stabilization device (SBS, SYS) does not affect the immediate reduction result and both stabilization methods are comparable in this respect.

The data have demonstrated a wide range of the orientation of the stabilization devices. However, the orientation does not influence the immediate congruity and the rate of asymmetrical syndesmotic reduction in side-to-side consideration analyzed in CT. Asymmetry in sagittal orientation was the most common failure of syndesmotic incongruity. This is comparable for both stabilization devices. Thus, the hypotheses have to be retained.

The AO recommends an oblique postero-fibular to antero-tibial angle of approximately $30^{\circ}$ for screw trajectory in transversal plain with the foot in a neutral dorsiflexion position with $20^{\circ}$ internal rotation $[22,33]$. Park et al. have shown that adjustment to the second toe, which is perpendicular to the ground is reliable methods, whereby the ideal angle of the device should be $18.8^{\circ}$ in transversal plain [8]. However, studies have shown a large interindividual variability in the anatomy of the distal syndesmosis, which could explain the large variance in the orientation of the stabilizing device despite standardized surgical technique [11, 17, 34-37].

Generally, there is limited evidence examining the relationship between the orientation of stabilization device and post-operative congruity of the syndesmosis. In contrast to our results, cadaver studies have demonstrated that the orientation of the stabilization device influences reduction result and varies depending on the entry point of the syndesmotic screw in the fibula [9]. Accordingly, a posterior orientation of syndesmotic fixation causes posterior translation and anteriorly oriented syndesmotic fixation causes anterior translation of the fibula with respect to the tibia [9]. Furthermore, Nimick et al. have found an anterior asymmetry of the syndesmosis in post-operative CT controls when the fixation was positioned anteriorly and a posterior asymmetry when the fixation was positioned more posteriorly. Based on their results, the authors recommended an orientation of stabilization device in the anterior third of the tibia in line with transmalleolar axis [18]. In the studies referred to above, the syndesmosis was reduced with reduction forceps before definitive fixation $[9,18]$. There is no description whether asymmetry had been ruled out during this step. Syndesmotic asymmetry has been shown to be related to the position of the 
reduction forceps $[9,19]$. A preliminary fixation with a deviation from the transmalleolar axis can provoke asymmetrical syndesmotic reduction $[9,19]$. Cosgrove et al. have demonstrated that a clamp position laterally centered on the fibula and medially on the anterior third of the tibia assessed at the talar dome most often results in anatomical reduction [19].

Because of interindividual anatomic differences in syndesmotic width and morphologic variants, bilateral CT control is superior to conventional radiography $[10,11,13,28$, $35,37]$. This has shown rates of syndesmotic malreduction between 0 and $42 \%$, with various definitions [5, 10, 14, 14]. In contrast to the literature, we could not show a superiority of the SBS compared to the SYS in this respect [10,14-16]. We explain our high rate of asymmetric syndesmosis reduction $(46 \%)$ by the separate evaluation of sagittal translation $(33 \%)$ and diastasis (10\%). Comparable to the literature, asymmetry in sagittal plane was most common in this analyzes, with $33 \%$ of cases [38]. For the chosen cut-off value of more than $2 \mathrm{~mm}$ in side-to-side comparison for evaluation as syndesmotic asymmetry, an association with worse postoperative results has been shown and is commonly referred to as malreduction. [5, 15]. Therefore, it is important to identify any preventable and correctable cause for asymmetries. But in spite of several studies, little is evident about the relationship between the rate of syndesmotic asymmetry and the orientation of the stabilization $[9,18,19]$. Our results have shown no causation between the orientation of the stabilization device and the syndesmotic congruity, neither in SYS nor SBS. In the SBS, asymmetrically dorsal translational was more frequent than in the SYS with the same rate of syndesmotic malreduction in the sagittal plane. It is controversial whether there is some spontaneous reduction of an asymmetry in sagittal plane in the SBS after weight bearing or bracing, respectively, after removal of SYS which should be taken into account if revision is considered [16, 39]. Therefore, the definition of an isolated malreduction in sagittal plane is not conclusive and further research on these patients is needed.

Based on these results, we assume that post-operative syndesmotic asymmetry is not primarily caused by deviation of the stabilization device from the ideal trajectory. Rather, it is influenced by the quality of bony reduction of the tibial and fibular fractures as well as the restoration of the tibiofibular congruity prior to syndesmotic fixation.

Along with the retrospective study design, one limitation of this study is that the CT scans are performed without stress or weight bearing. However, intraoperative CT imaging is gaining in importance, which is also unloaded. It has been shown that 2D measurements cannot fully describe the three-dimensional relationships of the syndesmosis as it is possible by weightbearing cone-beam CT (WBCT) [40, 41]. Yet, Hamard et al. have shown that unloaded multidetector computed tomography is more capable of distinguishing pathologic syndesmoses than WBCT [42]. On the one hand, the upright position causes a widening of normal ankle size; on the other hand, the injured leg is not fully loaded due to pain [42]. In the fracture situations, non-weightbearing cone-beam CT may offer a low-radiation alternative to multidetector CT [40].

Another limitation is that clinical outcomes were not assessed. Regardless, the primary objective of this retrospective CT analysis was to evaluate the influence of the orientation of syndesmotic stabilization device on immediate post-operative radiological outcomes. However, there was a wide range of IDAs, so there is a risk that the study might have been underpowered.

Further studies are required to analyze the influence of the orientation of the stabilization device on the clinical outcome. This question arises particularly in the context of implantation of an SBS, which is left in place, in contrast to the SYS, which is usually removed.

In conclusion, contrary to the available literature, we did not observe any correlation between the orientation of the stabilization device and the immediate post-operative congruity of the syndesmosis visualized in CT. Special attention should be paid to the careful intraoperative adjustment of the fibula in sagittal orientation. Based on the results, we assume that the quality of the bony reduction and the restoration of the tibiofibular congruity before syndesmotic fixation influences the post-operative position more than the orientation of the stabilization device itself.

Acknowledgements The authors would like to thank Mrs. A. Steller for her help in preparing the figures and Mr. M. Heinrich for lectorship.

Authors' contributions All authors contributed to the study conception and design. Data collection and analysis were performed by RH, UJS and ABA. The first draft of the manuscript was written by $\mathrm{RH}$ and ABA, all authors commented on previous versions of the manuscript. All authors read and approved the final manuscript.

Funding Open Access funding enabled and organized by Projekt DEAL. The authors received no financial support for the research, authorship, and/or publication of this article.

Availability of data and material The datasets used and/or analyzed during the current study are available from the corresponding author on reasonable request.

Code availability Not applicable.

\section{Declarations}

Conflict of interest The authors declare no conflict of interest with respect to the research, authorship, and/or publication of this article.

Ethics approval Approval of the local institutional review board for study had been given (Ethical Committee at the Medical Faculty, Leipzig University, AZ 488/19-ek) in view of the retrospective nature of 
the study and all the procedures being performed were part of the routine care.

Consent to participate All individuals have given general consent in the use of their data, including imaging, for analysis and publication. This has been approved by the Ethical Committee.

Consent for publication All individuals have given general consent in the use of their data, including imaging, for analysis and publication. This has been approved by the Ethical Committee.

Open Access This article is licensed under a Creative Commons Attribution 4.0 International License, which permits use, sharing, adaptation, distribution and reproduction in any medium or format, as long as you give appropriate credit to the original author(s) and the source, provide a link to the Creative Commons licence, and indicate if changes were made. The images or other third party material in this article are included in the article's Creative Commons licence, unless indicated otherwise in a credit line to the material. If material is not included in the article's Creative Commons licence and your intended use is not permitted by statutory regulation or exceeds the permitted use, you will need to obtain permission directly from the copyright holder. To view a copy of this licence, visit http://creativecommons.org/licenses/by/4.0/.

\section{References}

1. Elsoe R, Ostgaard SE, Larsen P (2018) Population-based epidemiology of 9767 ankle fractures. Foot Ankle Surg 24:34-39. https:// doi.org/10.1016/j.fas.2016.11.002

2. Tornetta P, Axelrad TW, Sibai TA, Creevy WR (2012) Treatment of the stress positive ligamentous SE4 ankle fracture: incidence of syndesmotic injury and clinical decision making. J Orthop Trauma 26:659-661. https://doi.org/10.1097/BOT.0b013e3182 $5 \mathrm{cf} 39 \mathrm{c}$

3. Egol KA, Pahk B, Walsh M et al (2010) Outcome after unstable ankle fracture: effect of syndesmotic stabilization. J Orthop Trauma 24:7-11. https://doi.org/10.1097/BOT.0b013e3181 b1542c

4. Ray R, Koohnejad N, Clement ND, Keenan GF (2019) Ankle fractures with syndesmotic stabilisation are associated with a high rate of secondary osteoarthritis. Foot Ankle Surg 25:180-185. https://doi.org/10.1016/j.fas.2017.10.005

5. Andersen MR, Diep LM, Frihagen F et al (2019) Importance of syndesmotic reduction on clinical outcome after syndesmosis injuries. J Orthop Trauma 33:397-403. https://doi.org/10.1097/ BOT.0000000000001485

6. van Vlijmen N, Denk K, van Kampen A, Jaarsma RL (2015) Long-term results after ankle syndesmosis injuries. Orthopedics 38:e1001-e1006. https://doi.org/10.3928/01477447-20151020-09

7. Buckley RE, Moran CG, Apivatthakakul T (2017) AO principles of fracture management, vol 1. George Thieme Verlag, Stuttgart, New York, ISBN 978-3-13-244473-7

8. Park YH, Choi WS, Choi GW, Kim HJ (2017) Ideal angle of syndesmotic screw fixation: A CT-based cross-sectional image analysis study. Injury 48:2602-2605. https://doi.org/10.1016/j. injury.2017.08.067

9. Miller AN, Barei DP, Iaquinto JM et al (2013) Iatrogenic syndesmosis malreduction via clamp and screw placement. J Orthop Trauma 27:100-106. https://doi.org/10.1097/BOT.0b013e3182 $5197 \mathrm{cb}$

10. Mukhopadhyay S, Metcalfe A, Guha AR et al (2011) Malreduction of syndesmosis-are we considering the anatomical variation?
Injury 42:1073-1076. https://doi.org/10.1016/j.injury.2011.03. 019

11. Dikos GD, Heisler J, Choplin RH, Weber TG (2012) Normal tibiofibular relationships at the syndesmosis on axial CT imaging. J Orthop Trauma 26:433-438. https://doi.org/10.1097/BOT.0b013 e3182535f30

12. Mendelsohn ES, Hoshino CM, Harris TG, Zinar DM (2014) CT Characterizing the anatomy of uninjured ankle syndesmosis. Orthopedics 37:e157-e160. https://doi.org/10.3928/0147744720140124-19

13. Gardner MJ, Demetrakopoulos D, Briggs SM et al (2006) Malreduction of the tibiofibular syndesmosis in ankle fractures. Foot Ankle Int 27:788-792. https://doi.org/10.1177/107110070602701 005

14. Sagi HC, Shah AR, Sanders RW (2012) The functional consequence of syndesmotic joint malreduction at a minimum 2-year follow-up. J Orthop Trauma 26:439-443. https://doi.org/10.1097/ BOT.0b013e31822a526a

15. Naqvi GA, Cunningham $P$, Lynch B et al (2012) Fixation of ankle syndesmotic injuries: comparison of TightRope fixation and syndesmotic screw fixation for accuracy of syndesmotic reduction. Am J Sports Med 40:2828-2835. https://doi.org/10.1177/03635 46512461480

16. Kortekangas T, Savola O, Flinkkilä $\mathrm{T}$ et al (2015) A prospective randomised study comparing TightRope and syndesmotic screw fixation for accuracy and maintenance of syndesmotic reduction assessed with bilateral computed tomography. Injury 46:11191126. https://doi.org/10.1016/j.injury.2015.02.004

17. Weening B, Bhandari M (2005) Predictors of functional outcome following transsyndesmotic screw fixation of ankle fractures. J Orthop Trauma 19:102-108. https://doi.org/10.1097/00005131200502000-00006

18. Nimick CJ, Collman DR, Lagaay P (2013) Fixation orientation in ankle fractures with syndesmosis injury. J Foot Ankle Surg 52:315-318. https://doi.org/10.1053/j.jfas.2013.02.005

19. Cosgrove CT, Putnam SM, Cherney SM et al (2017) Medial clamp tine positioning affects ankle syndesmosis malreduction. J Orthop Trauma 31:440-446. https://doi.org/10.1097/BOT.0000000000 000882

20. Meinberg E, Agel J, Roberts C et al (2018) Fracture and dislocation classification compendium-2018. J Orthop Trauma 32:S1S10. https://doi.org/10.1097/BOT.0000000000001063

21. Thordarson DB, Motamed S, Hedman T et al (1997) The effect of fibular malreduction on contact pressures in an ankle fracture malunion model*. J Bone Joint Surg 79:1809-1815. https://doi. org/10.2106/00004623-199712000-00006

22. Rüedi TP, Murphy WM (2000) AO principles of fracture management. George Thieme Verlag, Stuttgart, New York, AO Pub, ISBN 978-1588905567

23. Stoffel K, Wysocki D, Baddour E et al (2009) Comparison of two intraoperative assessment methods for injuries to the ankle syndesmosis: a cadaveric study. JBJS 91:2646-2652. https://doi. org/10.2106/JBJS.G.01537

24. Pakarinen H, Flinkkilä T, Ohtonen P et al (2011) Intraoperative assessment of the stability of the distal tibiofibular joint in supination-external rotation injuries of the ankle: sensitivity, specificity, and reliability of two clinical tests. J Bone Joint Surg 93:2057-2061. https://doi.org/10.2106/JBJS.J.01287

25. van den Bekerom MP (2011) Diagnosing syndesmotic instability in ankle fractures. WJO 2:51. https://doi.org/10.5312/wjo.v2.i7. 51

26. Cottom JM, Hyer CF, Philbin TM, Berlet GC (2008) Treatment of syndesmotic disruptions with the arthrex tightrope ${ }^{\text {tm }}$ : a report of 25 cases. Foot Ankle Int 29:773-780. https://doi.org/10.3113/ FAI.2008.0773 
27. Schon JM, Brady AW, Krob JJ et al (2019) Defining the three most responsive and specific CT measurements of ankle syndesmotic malreduction. Knee Surg Sports Traumatol Arthrosc 27:28632876. https://doi.org/10.1007/s00167-019-05457-8

28. Ahrberg AB, Hennings R, von Dercks N et al (2020) Validation of a new method for evaluation of syndesmotic injuries of the ankle. Int Orthop (SICOT) 44:2095-2100. https://doi.org/10. 1007/s00264-020-04631-9

29. Lepojärvi S, Pakarinen H, Savola O et al (2014) Posterior translation of the fibula may indicate malreduction: CT study of normal variation in uninjured ankles. J Orthop Trauma 28:205-209. https://doi.org/10.1097/BOT.0b013e3182a59b3c

30. Nault M-L, Hébert-Davies J, Laflamme G-Y, Leduc S (2013) CT Scan assessment of the syndesmosis: a new reproducible method. J Orthop Trauma 27:638-641. https://doi.org/10.1097/BOT.0b013 e318284785a

31. Kumar A, Passey J, Goel L et al (2020) New landmarks for ideal positioning of syndesmotic screw: a computerised tomography based analysis and radiographic simulation. Int Orthop (SICOT) 44:665-675. https://doi.org/10.1007/s00264-019-04467-y

32. Shrout PE, Fleiss JL (1979) Intraclass correlations: uses in assessing rater reliability. Psychol Bull 86:420-428. https://doi.org/10. 1037/0033-2909.86.2.420

33. Henkemeyer H, Püschel R, Burri C (1975) Experimentelle Untersuchungen zur Biomechanik der Syndesmose. In: 92. Kongreß der Deutschen Gesellschaft für Chirurgie, München, 7.-10. Mai 1975. Forumband, vol 75. Springer, Berlin, Heidelberg. https://doi.org/ 10.1007/978-3-662-05557-1_79

34. Bartonicek J (2003) Anatomy of the tibiofibular syndesmosis and its clinical relevance. Surg Radiol Anat 25:379-386. https://doi. org/10.1007/s00276-003-0156-4

35. Boszczyk A, Kwapisz S, Krümmel M et al (2019) Anatomy of the tibial incisura as a risk factor for syndesmotic injury. Foot Ankle Surg 25:51-58. https://doi.org/10.1016/j.fas.2017.08.003
36. Park CH, Kim GB (2019) Tibiofibular relationships of the normal syndesmosis differ by age on axial computed tomography-anterior fibular translation with age. Injury 50:1256-1260. https://doi. org/10.1016/j.injury.2019.04.022

37. Souleiman F, Heilemann M, Hennings R et al (2021) A standardized approach for exact CT-based three-dimensional position analysis in the distal tibiofibular joint. BMC Med Imaging 21:41. https://doi.org/10.1186/s12880-021-00570-y

38. Miller AN, Carroll EA, Parker RJ et al (2009) Direct visualization for syndesmotic stabilization of ankle fractures. Foot Ankle Int 30:419-426. https://doi.org/10.3113/FAI-2009-0419

39. Westermann RW, Rungprai C, Goetz JE et al (2014) The effect of suture-button fixation on simulated syndesmotic malreduction: a cadaveric study. J Bone Joint Surg 96:1732-1738. https://doi.org/ 10.2106/JBJS.N.00198

40. Burssens A, Vermue H, Barg A et al (2018) Templating of syndesmotic ankle lesions by use of 3D analysis in weightbearing and nonweightbearing CT. Foot Ankle Int 39:1487-1496. https://doi. org/10.1177/1071100718791834

41. Barg A, Bailey T, Richter M et al (2018) Weightbearing computed tomography of the foot and ankle: emerging technology topical review. Foot Ankle Int 39:376-386. https://doi.org/10.1177/10711 00717740330

42. Hamard M, Neroladaki A, Bagetakos I et al (2020) Accuracy of cone-beam computed tomography for syndesmosis injury diagnosis compared to conventional computed tomography. Foot Ankle Surg 26:265-272. https://doi.org/10.1016/j.fas.2019.03.006

Publisher's Note Springer Nature remains neutral with regard to jurisdictional claims in published maps and institutional affiliations. 